\title{
ACTITUDES ANTE LA INVERSIÓN EXTRANJERA: EL CASO DE MÉXICO
}

\author{
ana Carolina Garriga \\ Marc Grau Vidiella
}

\section{INTRODUCCIÓN}

¿QUÉ OPINAN LOS MEXICANos sobre la inversión extranjera? El objetivo de este artículo es describir las opiniones de los mexicanos sobre distintos aspectos relacionados con la inversión extranjera. En particular, se analizan las encuestas de México, las Américas y el Mundo para estudiar las actitudes de los encuestados sobre cuáles son los efectos de la inversión extranjera para México, qué tan importante es que la atracción de inversión extranjera sea un objetivo prioritario de la política exterior y en qué sectores de la economía debería permitirse la inversión por parte de extranjeros.

Este estudio, si bien de tenor descriptivo, presenta una contribución tanto teórica como práctica. Desde el punto de vista teórico, la ola de reformas liberales avivó el interés por comprender mejor la dirección y los determinantes de la opinión pública respecto de las políticas de apertura o liberalización. Este interés se manifestó tanto entre los especialistas en política comparada ${ }^{1}$ como entre los estudiosos de la economía política internacional. ${ }^{2}$ Sin embargo, tal

${ }^{1}$ Por ejemplo, Susan Stokes (ed.), Public Support for Market Reforms in New Democracies, Cambridge Studies in Comparative Politics, Cambridge / Nueva York, Cambridge University Press, 2001.

${ }^{2}$ Véanse, entre otros, Andy Baker, "Why Is Trade Reform so Popular in Latin America?: A Consumption-Based Theory of Trade Policy Preferences", World Politics, vol. 55, núm. 3, 2003; Kenneth Scheve y Matthew Slaughter, "What Determines Individual Trade-Policy Preferences?”, Journal of International Economics, vol. 54, núm. 2, 2001. 
como se discute más adelante, sabemos poco sobre cuáles son las actitudes de la ciudadanía frente a la inversión extranjera. Aun cuando los estudios sobre opinión pública en México están muy difundidos, ${ }^{3}$ estos trabajos tienden a centrarse en el estudio del comportamiento electoral, con menos ejemplos de factores que informan la opinión sobre procesos económicos y sus consecuencias. ${ }^{4}$ Sostenemos que una descripción profunda e informada teóricamente es un paso preliminar para la indagación sobre factores causales que permitan entender estas configuraciones de opiniones. Por eso consideramos que un estudio descriptivo constituye un aporte relevante para la elaboración de teoría en un área de investigación en desarrollo.

Desde el punto de vista práctico, la bibliografía en economía política presenta evidencia sobre la voluntad de los gobiernos de atraer inversión extranjera. Algunos estudios muestran que la inversión extranjera mejora el crecimiento económico, ${ }^{5}$ especialmente

${ }^{3}$ Por ejemplo, Rosario Aguilar, “¿Emociones y razón?: el uso estratégico de emociones en los anuncios de la campaña presidencial de 2012”, Política y Gobierno, vol. 20, núm. 1, 2013; Jorge Buendía Laredo y Ma. Fernanda Somuano, "Participación electoral en nuevas democracias: la elección presidencial de 2000 en México", Política y Gobierno, vol. 10, núm. 2, 2003; Kenneth Greene, "Campaign Persuasion and Nascent Partisanship in Mexico's New Democracy”, American Journal of Political Science, vol. 55, núm. 2, 2011; Chappell Lawson y James McCann, "Television News, Mexico's 2000 Elections and Media Effects in Emerging Democracies", British Journal of Political Science, vol. 35, núm. 1, 2005; Alejandro Moreno, El votante mexicano: democracia, actitudes políticas y conducta electoral, México, FCE, 2003; Alejandro Moreno, La decisión electoral. votantes, partidos y democracia en México, México, Porrúa, 2009.

${ }^{4}$ Por ejemplo, ninguno de los artículos publicados en la Revista Mexicana de Opinión Pública analiza la opinión pública mexicana frente a la inversión extranjera. De hecho, sólo uno de los artículos describe actitudes de los mexicanos frente a cuestiones económicas con impacto en la política exterior: Rafael Velázquez Flores y Jorge Schiavon, “Opinión pública y política exterior: percepciones y preferencias de los mexicanos”, Revista Mexicana de Opinión Pública, vol. 4, núm. abril de 2008.

5 Xiaoying Li y Xiaming Liu, "Foreign Direct Investment and Economic Growth: An Increasingly Endogenous Relationship", World Development, vol. 33, núm. 3, 2005; Theodore Moran, Beyond Sweatshops, Washington, Brookings Institution Press, 2002. 
en países que reciben inversión extranjera destinada a exportaciones. ${ }^{6}$ Otros estudios asocian la inversión extranjera con mayor inversión doméstica, ${ }^{7}$ menores niveles de pobreza ${ }^{8}$ y de desigualdad en el ingreso dentro del país receptor de la inversión, ${ }^{9}$ y con la productividad del trabajo. ${ }^{10}$ Sin embargo, es posible que la opinión de los ciudadanos sobre la inversión extranjera no coincida con los hallazgos en la literatura académica. Razones ideológicas, económicas o personales pueden influir las opiniones sobre los beneficios asociados a la inversión extranjera o sobre la conveniencia de políticas de promoción de inversión extranjera. En este sentido, este artículo presenta evidencia para la toma de decisiones más informada sobre las preferencias los mexicanos.

Este trabajo utiliza los datos de opinión sobre inversión extranjera recabados por la encuesta México, las Américas y el Mundo, un sondeo bienal aplicado al público y a líderes en México sobre política exterior y relaciones internacionales. ${ }^{11}$ Las respuestas a las preguntas de interés fueron recolectadas en los años 2004, 2006, 2008, 2010 y 2012 en todo el territorio mexicano. Esto hace al estudio especialmente comprehensivo y permite identificar variaciones en la tendencia a lo largo del tiempo. Este análisis nos permite identificar patrones temporales en las opiniones hacia la inversión extranjera, marcadas diferencias regionales (incluso teniendo en

${ }^{6}$ Kevin Honglin Zhang, "Does Foreign Direct Investment Promote Economic Growth? Evidence from East Asia And Latin America", Contemporary Economic Policy, vol. 19, núm. 2, 2001.

7 Ashoka Modya y Antu Panini Murshid, "Growing Up with Capital Flows", Journal of International Economics, vol. 65, 2005; Eduardo Borensztein et al., "How Does Foreign Direct Investment Affect Economic Growth?”, Journal of International Economics, vol. 45, 1998.

${ }^{8}$ Jagdish Bhagwati, "Why Multinationals Help Reduce Poverty", World Economy 30, núm. 2, 2007.

${ }^{9}$ Nathan Jensen y Guillermo Rosas, "Foreign Direct Investment and Income Inequality in Mexico, 1990-2000”, International Organization, vol. 61, núm. 3, 2007.

${ }^{10}$ José Romero, "Inversión extranjera directa y crecimiento económico en México: 1940-2010”, Documento de Trabajo, núm. 12, Mexico, El Colegio de México, 2012.

11 Véase http://mexicoyelmundo.cide.edu. En este trabajo sólo analizamos las encuestas al público. 
cuenta distintas tasas de desempleo regionales) e inconsistencias en las opiniones sobre los beneficios asociados con la inversión extranjera y las preferencias de política relacionadas con la inversión extranjera.

\section{2. ¿Por QUé estudiar las actitudes hacia la inVersión EXTRANJERA?}

Conocer las actitudes es importante para la toma de decisiones, tanto para los gobernantes como para los inversionistas. El supuesto detrás de la planificación de políticas públicas en regímenes democráticos es que los intereses de la sociedad son tenidos en cuenta. En ese marco, es central conocer las demandas de la sociedad, tanto para el diseño de políticas que respondan a las demandas de la ciudadanía, como para mejorar la justificación y comunicación de las políticas que se implementen.

El estudio de las actitudes hacia la inversión extranjera también es importante para el sector privado. Invertir en un país foráneo se relaciona con una serie de riesgos, entre los que se encuentran no sólo el riesgo económico (asociado con la estabilidad macroeconómica y cambiaria del país una vez realizada la inversión) y el riesgo político (la posibilidad de que cambios en las reglas del juego alteren los términos de la inversión), sino también el riesgo derivado de las actitudes en contra de la inversión extranjera que pueden afectar la estabilidad y rentabilidad de las inversiones. Algunos estudios han señalado que la opinión pública y preferencias acerca de la inversión extranjera directa afectan las decisiones de locación de las empresas multinacionales. ${ }^{12}$ En particular, Jakobsen y Jakobsen encuentran que el nacionalismo económico

12 Jo Jakobsen y Tor Jakobsen, "Economic Nationalism and FDI: The Impact of Public Opinion on Foreign Direct Investment in Emerging Markets, 19902005", Society and Business Review, vol. 6, núm. 1, 2011; Tor Jakobsen, "Economic Nationalism and Foreign Direct Investment. A Great Risk for Investors", http:/ / www.popularsocialscience.com/2012/11/26/economic-nationalism-and-foreigndirect-investment-a-great-risk-for-investors/ 
desalienta la inversión en países en vías de desarrollo. ${ }^{13}$ Una opinión pública que rechaza la inversión extranjera puede ocasionar temores de posibles boicots de consumidores, problemas para contratar trabajadores y de eventuales cambios en la política de los gobiernos que respondan a presiones populares o cambios en el humor de los votantes.

\section{LAS ACTITUDES HACIA LA INVERSIÓN EXTRANJERA EN LA LITERATURA}

Los estudios sobre actitudes hacia política exterior en materia económica son relativamente recientes. El grupo más importante de trabajos indaga las actitudes hacia la globalización económica, muchas veces definida como apertura comercial ${ }^{14}$ o como integración económica. ${ }^{15}$ Estos trabajos intentan determinar qué factores se asocian al apoyo de políticas de apertura al comercio internacional o de políticas proteccionistas.

Se han utilizado dos modelos clásicos de comercio internacional para derivar preferencias individuales en relación con la apertura comercial. El modelo Ricardo-Viner (o de factores específicos) supone que los factores de la producción tienen poca movilidad, por lo que la renta de los factores (y consecuentemente, las preferencias individuales en favor o en contra de la apertura comercial)

13 Jakobsen y Jakobsen, "Economic Nationalism and FDI...".

${ }^{14}$ Por ejemplo, Andy Baker, "Who Wants to Globalize? Consumer Tastes and Labor Markets in a Theory of Trade Policy Beliefs", American Journal of Political Science, vol. 49, núm. 4, 2005; Benjamin Fordham y Katja Kleinberg, "How Can Economic Interests Influence Support for Free Trade?”, International Organization, vol. 66, núm. 2, 2012; Gordon Hanson et al., "Public Finance and Individual Preferences Over Globalization Strategies”, Economics E̊ Politics, vol. 19, núm. 1, 2007.

${ }^{15}$ Hyeok Kwon, "Globalization, Cultural Openness, and Public Preferences for East Asian Economic Integration in South Korea", International Journal of Public Opinion Research, vol. 23, núm. 1, 2011; Raymond Hicks et al., "Trade Policy, Economic Interests, and Party Politics in a Developing Country: The Political Economy of CAFTA-DR", International Studies Quarterly, 2013; Mitchell Seligson, "Popular Support for Regional Economic Integration in Latin America”, Journal of Latin American Studies, vol. 31, núm. 1, 1999. 
está determinada crucialmente por la industria (o sector) ${ }^{16}$ en la que el individuo trabaje. Por el contrario, el modelo Heckscher -Ohlin postula la movilidad de los factores de la producción entre distintas industrias, por lo que las preferencias comerciales se basan en el factor de producción de que se trate (por ejemplo, capital o trabajo) y la abundancia relativa de ese factor en su país.

Varios trabajos han puesto a prueba hasta qué punto las preferencias individuales en materia comercial responden a las predicciones derivadas de estos modelos generales. Aunque en algunos casos se presenta evidencia que apoya el modelo de factores (Heckscher-Ohlin), ${ }^{17}$ también se hace evidente que hay una serie de factores que influyen estas preferencias y que van más allá de la posición del individuo en la economía. ${ }^{18}$ Por ejemplo, Scheve y Slaughter muestran que el modelo de factores tiene mayor influencia que el modelo basado en la industria sobre las preferencias individuales en materia de comercio internacional. Sin embargo, estas preferencias también se ven afectadas por tener su propiedad en condados cuya producción sea perjudicada por el comercio

${ }^{16}$ En el marco del modelo Ricardo-Viner se entiende por industria al conjunto de actividades vinculadas a la producción de un tipo específico de bienes (por ejemplo, industria alimenticia, metalmecánica, textil, etc.). En algunas traducciones, industria y sector se emplean de manera indistinta. En este contexto, industria no equivale a actividades de transformación de materia prima (lo que frecuentemente se entiende como "actividades industriales").

${ }^{17}$ Nótese que esta no es una conclusión generalizada. Hay estudios que encuentran apoyo para el modelo de factores específicos (Hicks et al., "Trade Policy, Economic Interests, and Party Politics in a Developing Country: The Political Economy of CAFTA-DR"). Otros estudios no encuentran apoyo para ninguno de los dos modelos citados (Edward Mansfield y Diana Mutz, "Support for Free Trade: SelfInterest, Sociotropic Politics, and Out-Group Anxiety", International Organization, vol. 63, núm. 3, 2009). Finalmente, otros muestra que las relaciones entre ambos modelos son más complejas de lo que se ha supuesto hasta el momento (Bumba Mukherjee et al., "Labor (Im) mobility and the Politics of Trade Protection in Majoritarian Democracies”, The Journal of Politics, vol. 71, núm. 1, 2009).

18 Edward Balistreri, "The Performance of the Heckscher-Ohlin-Vanek Model in Predicting Endogenous Policy Forces at the Individual Level", Canadian Journal of Economics, vol. 30, núm. febrero de 1997; Anna Maria Mayda y Dani Rodrik, "Why Are Some People (and Countries) More Protectionist than Others?", European Economic Review, vol. 49, núm. 6, 2005. 
internacional, lo que sugiere que las preferencias comerciales también responden a cambios en el valor de sus activos. ${ }^{19}$ Incorporando otros factores al análisis, O'Rourke y Sinnott encuentran que las preferencias por políticas proteccionistas se asocian con fuertes sentimientos de identidad nacional y actitudes nacionalistas. ${ }^{20}$

Además de lo anterior, dos factores aparecen consistentemente asociados con actitudes menos proteccionistas. Por un lado, niveles de conocimiento más altos, sean en general o en relación con la calificación (potencial) de la mano de obra, se asocian con actitudes menos proteccionistas. En tal sentido, Hiscox muestra que los individuos con más años de escolarización son más propensos a apreciar los beneficios de la integración, especialmente aquellos que han sido expuestos a la teoría comercial y al principio de ventaja comparativa. ${ }^{21}$ Asimismo, Ardañaz, Murillo y Pinto presentan evidencia señalando que la calificación de la mano de obra es un predictor central para el apoyo de la apertura. Este efecto se asocia también con una menor sensibilidad de las respuestas a cambios en el marco (o framing) de las preguntas. ${ }^{22}$ Por otro lado, la literatura encuentra consistentemente que las mujeres son más proteccionistas que los hombres, aunque esta relación entre género y proteccionismo está menos teorizada. ${ }^{23}$

La bibliografía que estudia las actitudes hacia la inversión extranjera es menos numerosa y más reciente. En gran medida, su desarrollo ha respondido al intento de aplicar teorías que explican

${ }^{19}$ Scheve y Slaughter, "What Determines Individual Trade-Policy Preferences?".

${ }^{20}$ Kevin O'Rourke y Richard Sinnott, “The Determinants of Individual Trade Policy Preferences: International Survey Evidence”, Brookings Trade Forum, 2001.

${ }^{21}$ Michael Hiscox, "Through a Glass and Darkly: Attitudes toward International Trade and the Curious Effects of Issue Framing”, International Organization, vol. 60, núm. 3, 2006.

${ }^{22}$ Martin Ardanaz et al., "Sensitivity to Issue Framing on Trade Policy Preferences: Evidence from a Survey Experiment", International Organization, vol. 67, núm. 2, 2013.

${ }^{23}$ Michael Hiscox y Brian Burgoon, "The Mysterious Case of Female Protectionism: Gender Bias in Attitudes Towards Globalization”, American Political Science Association, Philadelphia, 2003; O'Rourke y Sinnott, "The Determinants of Individual Trade Policy Preferences: International Survey Evidence”; Seligson, "Popular Support for Regional Economic Integration in Latin America". 
las preferencias comerciales a las preferencias sobre inversión. Sin embargo, estos desarrollos se han visto limitados por la falta de datos sobre actitudes hacia la inversión extranjera.

La mayoría de estos estudios argumenta que las actitudes hacia la inversión extranjera están fuertemente influidas por los efectos de la inversión extranjera sobre el ingreso. Scheve y Salughter sostienen que, en economías más desarrolladas, la globalización aumenta la inseguridad de los trabajadores, y que la inversión extranjera directa es un sustituto de la mano de obra doméstica, lo que la convierte en un factor central responsable de mayores riesgos para los trabajadores. Esto se debe a que la inversión extranjera directa aumenta la elasticidad de la demanda de trabajo. Una demanda de trabajo más elástica incrementa la volatilidad de los salarios y del empleo, lo cual aumenta la sensación de inseguridad de los trabajadores. ${ }^{24}$

Analizando el caso de los países en vías de desarrollo, Sonal Pandya sostiene que la inversión extranjera directa se asocia con salarios más altos porque las empresas extranjeras demandan una mano de obra más calificada que las empresas locales. Por ello, el apoyo a la inversión extranjera debería ser más alto en trabajadores más calificados. ${ }^{25}$ Esto es consistente con lo que sostiene Pinto, quien ve a la inversión extranjera directa y a la mano de obra como complementarias en economías en desarrollo, por lo que las actitudes de la mano de obra menos calificada deberían ser más positivas hacia la inversión extranjera. ${ }^{26}$

Sin embargo, un estudio reciente cuestiona el supuesto de información completa de los individuos, que los haría tener opiniones frente a la apertura (comercial, en este caso) consistentes con su posición en la economía (factor de producción que los ocupa). ${ }^{27}$

${ }^{24}$ Kenneth Scheve y Matthew Slaughter, "Economic Insecurity and the Globalization of Production”, American Journal of Political Science, vol. 48, núm. 4, 2004.

${ }^{25}$ Sonal Pandya, "Labor Markets and the Demand for Foreign Direct Investment”, International Organization, vol. 64, núm. 3, 2010.

${ }^{26}$ Pablo Pinto, Partisan Investment in the Global Economy: Why the Left Loves Foreign Direct Investment and FDI Loves the Left, Cambridge, Cambridge University Press, 2013.

${ }^{27}$ Juan Díez Medrano y Michael Braun, "Uninformed Citizens and Support for Free Trade”, Review of International Political Economy, vol. 19, núm. 3, 2011. 
Medrano y Braun sugieren que la mayoría de los individuos carece de esta información, por lo que sus opiniones en relación con los beneficios de la apertura reflejan más la información que reciben por otros medios, los marcos en que las preguntas se presentan (framing), la vulnerabilidad económica y su inclinación política. ${ }^{28}$ En esta línea se enmarcan los resultados encontrados por Kocher y Minushkin, que sugieren que las expectativas racionales respecto a la situación económica no son determinantes importantes de las actitides hacia la inversión extranjera en México. ${ }^{29}$ En particular, ellos encuentran que actitudes que reflejan antiamericanismo se asocian con opiniones negativas hacia la inversión extranjera. ${ }^{30}$

Esta breve revisión de la bibliografía que directa o indirectamente se refiere a las actitudes sobre la inversión extranjera sugiere las siguientes hipótesis. Primero, en países en vías de desarrollo, relativamente abundantes en mano de obra, la inversión extranjera se asocia a beneficios en materia de empleo. Con base en la literatura económica, y suponiendo información de los individuos sobre su posición en la economía, individuos que viven en países en vías de desarrollo deberían percibir mayores beneficios asociados a la inversión extranjera, y ser más propensos a favorecer políticas de atracción de inversiones. Este efecto debería ser más intenso en regiones con niveles de desempleo más altos.

Segundo, si la opinión sobre los beneficios asociados a la inversión extranjera se basa principalmente en factores objetivos, debería observarse cierta consistencia entre la opinión sobre los beneficios asociados con la inversión extranjera y las preferencias de política relacionadas con la inversión extranjera. En tercer lugar, esperamos que, especialmente en el caso de México, la geografía sea un factor importante a tener en cuenta: una mayor proximidad y contacto con los Estados Unidos debería influir sobre las opiniones frente a la inversión extranjera. La literatura, sin embargo, no sugiere qué efecto puede

28 Ibid.

${ }^{29}$ Matthew Adam Kocher y Susan Minushkin, “Antiamericanismo y globalización económica: libre comercio, apertura de mercados y opinión pública en México”, Política y Gobierno, vol. 14, núm. 1, 2007.

${ }^{30} \mathrm{Ibid}$. 
tener la distancia de los Estados Unidos sobre las opiniones que aquí analizamos.

\section{ANÁlisis de las aCtitudes hacia la inVERsión extranjera en México}

México tiene una relación particular con la inversión extranjera. Durante el Porfiriato (1877-1910) se buscó activamente el capital foráneo en el desarrollo de la industria nacional. La Constitución de 1917 introdujo en la legislación la idea de la propiedad nacional de los recursos provenientes del territorio nacional. En 1938, Cárdenas nacionalizó la industria petrolera y abrió un periodo de severas limitaciones a la participación extranjera en numerosos sectores de la economía, incluyendo la explotación de recursos naturales, la propiedad de inmuebles y la industria bancaria. ${ }^{31}$ La ley de inversión extranjera de $1973^{32}$ establecía los sectores de participación exclusiva del Estado (incluyendo petróleo, hidrocarburos, electricidad, ferrocarriles y minería) y los sectores de participación reservada a mexicanos (incluyendo radio, televisión transporte aéreo y explotación forestal), además de dar al Estado poderes discrecionales para regular la inversión extranjera. A partir de la década de 1980, la política económica da un giro hacia la liberalización que se ve reflejado en la búsqueda del libre comercio internacional y la reforma en la legislación que regulaba la inversión extranjera. ${ }^{33}$ Durante este periodo se liberalizó la inversión extranjera en la banca, la minería, las telecomunicaciones, entre otros sectores; en tanto que el Estado mantuvo su participación exclusiva en la industria petrolera y de hidrocarburos y energética.

${ }^{31}$ Enrique Dussel Peters, "La inversión extranjera en México", Series de Desarrollo Productivo CEPAL, núm. 80, Santiago de Chile, Naciones Unidas, 2000.

32 "Ley para promover la Inversión Mexicana y regular la Inversión Extranjera” (Diario Oficial de la Federación, 1973).

33 "Reglamento de la Ley para promover la Inversión Mexicana y regular la Inversión Extranjera" (Diario Oficial de la Federación, 1989) y la "Ley de Inversión Extranjera" (Diario Oficial de la Federación, 1993) y su posterior reforma en 1996, y reglamento de 1998. 
Entre 2004 y 2012 México ha recibido más de 400000 millones de dólares en inversión extranjera, de los cuales aproximadamente la mitad corresponde a inversión extranjera directa. La inversión extranjera directa tiende a concentrarse en los grandes centros económicos del país, dejando de lado los estados del sur del país (con la excepción de Quintana Roo). En términos absolutos, el D. F. acapara casi la mitad de la inversión extranjera directa recibida por México, seguido de Nuevo León y el Estado de México. Les siguen los estados de Baja California, Baja California Sur, Jalisco y Chihuahua. En términos relativos (inversión extranjera directa como porcentaje del PIB estatal), el D. F. y Baja California Sur reciben los porcentajes más altos de inversión, seguidos de Nuevo León y Chihuahua. ${ }^{34}$

Este trabajo analiza los resultados de las encuestas de México, las Américas y el Mundo para conocer las actitudes de los ciudadanos hacia la inversión extranjera. Esta encuesta, diseñada y publicada por el Centro de Investigación y Docencia Económicas, se lleva adelante cada dos años en todo el territorio nacional (véase las fechas de levantamiento en tabla 1), y tiene por objetivo general evaluar las percepciones de los mexicanos hacia los temas de política exterior y relaciones internacionales. ${ }^{35} \mathrm{La}$ encuesta incluye entre 1499 (en 2006) y 2390 (de 2008 a 2012) entrevistas estructuradas personales "cara a cara" en viviendas particulares a mexicanos de dieciocho años o más con residencia en cualquier entidad del territorio nacional. ${ }^{36} \mathrm{El}$ cuestionario incluye alrededor de ochenta preguntas (en la edición de 2012) que indagan las opiniones sobre

34 Ana Carolina Garriga, "Política partidaria e inversión extranjera directa: el caso de los estados mexicanos", Documento de Trabajo DTEP, núm. 256, México, Centro de Investigación y Docencia Económicas, 2013.

${ }^{35}$ Esta encuesta involucra a una red de instituciones académicas en dieciocho países. Como parte de este proyecto se han levantado encuestas similares en otros países de Latinoamérica. Para mayor información sobre las características, instrumentos y resultados de las distintas ediciones de la encuesta en México y en otros países, véase http://www.lasamericasyelmundo.org/

${ }^{36}$ En la edición de 2010 se omitió al estado de Tamaulipas y once municipios de Michoacán por razones de seguridad de los entrevistadores. El diseño de muestreo de las encuestas de 2008, 2010 y 2012 incluyó una sobre-muestra de las regiones norte y sureste. 
diversos aspectos de las relaciones internacionales, incluyendo la política exterior, el contacto con el exterior, las relaciones con países en particular o las reglas de juego internacionales. A lo largo de los cuestionarios de las distintas ediciones una serie de preguntas examinan la opinión sobre la inversión extranjera que analizamos en este documento.

\section{TABLA 1}

Resumen de las características de la encuesta

\begin{tabular}{|c|c|c|c|c|c|}
\hline \multirow[b]{2}{*}{ Edición } & \multirow{2}{*}{$\begin{array}{c}\text { Fechas de } \\
\text { levantamiento }\end{array}$} & \multicolumn{4}{|c|}{ Número de entrevistas (error) } \\
\hline & & Total & Norte & Centro & Sureste \\
\hline 2004 & Del 9/07 al 19/07 & $1500( \pm 4 \%)$ & $600( \pm 6 \%)$ & $600( \pm 6 \%)$ & $300( \pm 8 \%)$ \\
\hline 2006 & Del 22/07 al 27/07 & $1499( \pm 4 \%)$ & $600( \pm 6 \%)$ & $600( \pm 6 \%)$ & $299( \pm 8 \%)$ \\
\hline 2008 & Del 14/08 al 6/09 & $2400( \pm 2 \%)$ & $730( \pm 3.7 \%)$ & $1180( \pm 2.9 \%)$ & $480( \pm 4.5 \%)$ \\
\hline 010 & Del 27/09 al 29/10 & $2400( \pm 2 \%)$ & $730( \pm 3.7 \%)$ & $1180( \pm 2.9 \%)$ & $480( \pm 4.5 \%)$ \\
\hline 2012 & Del 18/08 al 20/09 & $2400( \pm 2 \%)$ & $730( \pm 3.7 \%)$ & $1180( \pm 2.9 \%)$ & $480( \pm 4.5 \%)$ \\
\hline
\end{tabular}

La encuesta es representativa a nivel nacional y para cada una de las siguientes tres regiones: la región norte, que comprende los estados de Baja California, Coahuila, Chihuahua, Nuevo León, Sonora y Tamaulipas; la región sureste, que comprende los estados de Campeche, Chiapas, Guerrero, Oaxaca, Quintana Roo, Tabasco y Yucatán; y la región compuesta por el resto del país. La tabla 1 presenta información sobre fechas de levantamiento de las encuestas, el número de entrevistas realizadas y el error de estimación por diseño de la muestra. El anexo 1 describe las preguntas y las opciones de respuesta utilizadas en este artículo.

\subsection{La inversión extranjera: ¿beneficia a México?}

La primera pregunta que nos interesa analizar es la que se refiere a los potenciales beneficios aparejados a la inversión extranjera. Como se mencionó anteriormente, las investigaciones sugieren que la inversión extranjera está asociada con una serie de externalidades 
positivas. Sin embargo, es posible que las percepciones de la ciudadanía se alejen de los análisis realizados en el área de economía política internacional y se vea influida por otros factores. Este apartado presenta los resultados frente a la pregunta "¿Qué tanto cree usted que la inversión extranjera beneficia a México?”, destacando particularmente la variación temporal y regional de las opiniones en este tema.

Si consideramos los cinco levantamientos en su conjunto, $73.7 \%$ de los encuestados consideran que la inversión extranjera trae beneficios a México; $40 \%$ de los encuestados están convencidos de que la inversión extranjera beneficia mucho, en tanto que $33.5 \%$ creen que la inversión extranjera beneficia en algo al país. El resto de las respuestas se divide entre $20.5 \%$ de los entrevistados que cree que la inversión extranjera trae pocos beneficios, y un $5.8 \%$ de la muestra que no cree que la inversión extranjera sea beneficiosa para México. Estos niveles son más bajos que los obtenidos en Colombia en los años 2008 y 2010, por ejemplo, en donde $83 \%$ de los encuestados creen que la inversión extranjera beneficia mucho o algo a Colombia ( 46 y $37 \%$ respectivamente) ${ }^{37}$

Sin embargo, los porcentajes sobre el total de las entrevistas realizadas en las cinco encuestas en México oscurecen cierta variación a lo largo del tiempo. La gráfica 1 muestra el porcentaje de respuestas obtenidas por cada opción en los cinco levantamientos de la encuesta en México. Como puede observarse, la creencia en que la inversión extranjera se asocia con beneficios para México tuvo su punto más bajo en 2004, cuando $43.6 \%$ de los encuestados mexicanos opinaron que la inversión extranjera no traía o traía pocos beneficios para el país, seguido por los resultados de la encuesta 2008, en los que ese grupo representó 35.9\% de la muestra. En cambio, en los levantamientos de 2006 y 2010 el porcentaje de entrevistados que opinó que la inversión extranjera beneficia "mucho" o "algo" está muy por encima de quienes tuvieron una opinión

${ }^{37}$ Arlene Tickner y Felipe Botero, Colombia y el mundo 2010. Opinión pública y política internacional, Bogotá, Universidad de los Andes, 2011. Este estudio también emplea datos del proyecto Las Américas y el Mundo: Opinión Pública y Política Exterior. 
negativa. En 2012 la tendencia es similar con la excepción de que el porcentaje de quienes respondieron "algo" supera por primera vez al porcentaje de quienes respondieron "mucho". Se puede observar que el grupo de los muy escépticos (quienes respondieron "nada") mantiene un porcentaje relativamente constante y menor a $10 \%$ en todos los años. A pesar de las variaciones en los levantamientos de 2004 y 2006 , la tendencia general es que existe una mayoría que mantiene opiniones positivas sobre los beneficios de la inversión extranjera a lo largo del tiempo.

\section{GRÁFICA 1}

¿Qué tanto cree usted que la inversión extranjera beneficia a México?

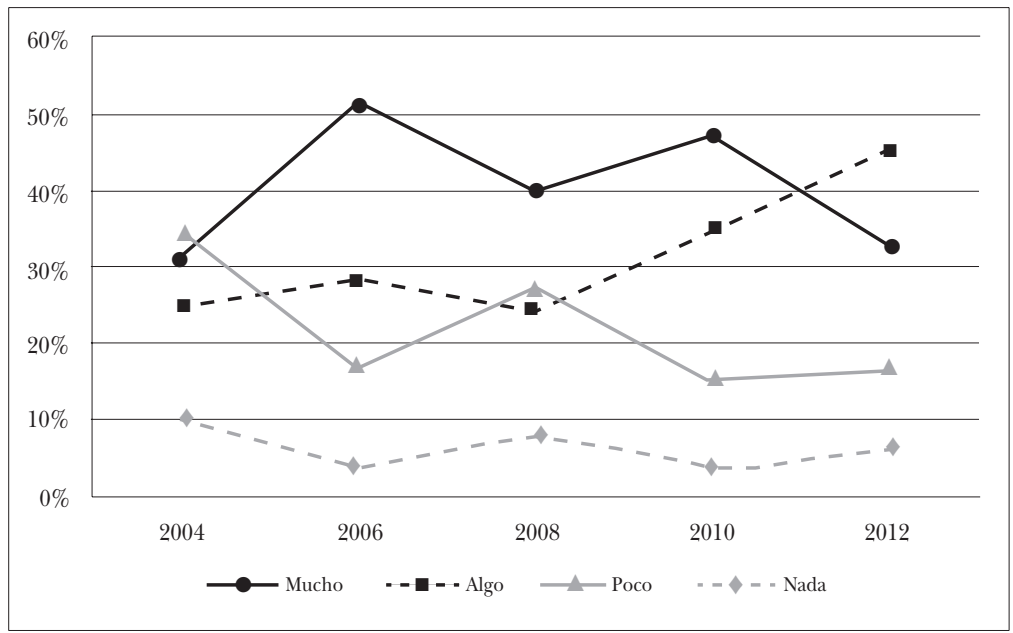

Las actitudes frente a los beneficios que acarrea la inversión extranjera difieren marcadamente en las distintas regiones del país. Los entrevistados en los estados del norte del país tienen opiniones más positivas respecto del impacto que tiene la inversión extranjera en México, en tanto que los encuestados en los estados del sureste del país tienen la visión menos optimista. 
La gráfica 2 representa estas diferencias regionales. A fin de simplificar la visualización de los datos, esta gráfica colapsa las respuestas que reflejan una opinión positiva frente a la inversión extranjera (aquellos encuestados que consideran que la inversión extranjera trae muchos o algunos beneficios para México) y las divide por regiones. Como puede observarse, los entrevistados en la región norte del país tienen una visión significativamente más positiva de la inversión extranjera, con una diferencia que va desde los 5.46 puntos porcentuales (en 2004) y llega hasta los 20.39 puntos porcentuales de diferencia (en 2008) en comparación con la región denominada "resto del país". Las diferencias de opinión son más pronunciadas si se compara la opinión positiva respecto de la inversión extranjera de los entrevistados en el norte con el sureste, en donde la aceptación en las cinco encuestas se encuentra, en promedio, unos 17.4 puntos porcentuales por debajo de la aceptación en el norte.

GRÁFICA 2

¿Qué tanto cree usted que la inversión extranjera beneficia a México?

\% de encuestados que respondieron "Mucho" o "Algo"

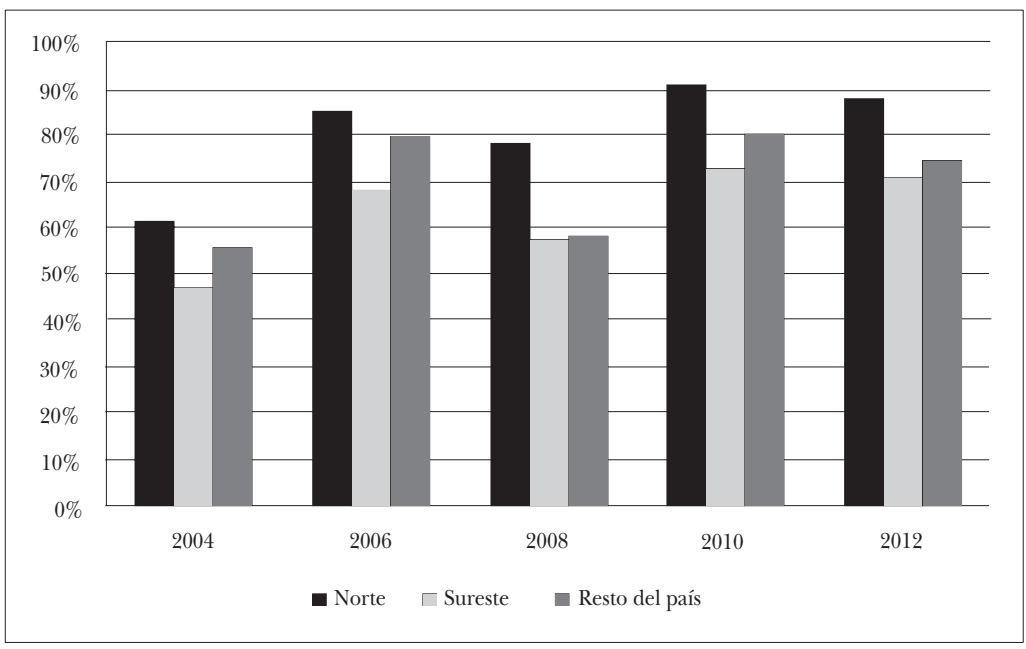


Varios factores podrían explicar esta variación regional. Por un lado, un mayor contacto con Estados Unidos, el principal país de origen de la inversión extranjera que llega a México, puede favorecer una opinión más positiva hacia el fenómeno. Asimismo, existen diferencias socioeconómicas y en el nivel de escolarización entre las regiones norte y sur del país que pueden explicar en parte esta diferencia. Otra explicación es la relacionada con la disponibilidad relativa del factor trabajo. Como señalamos anteriormente, la teoría económica sugiere que en países en vías de desarrollo, que son relativamente abundantes en mano de obra, la inversión extranjera debería beneficiar más al factor trabajo. Aun cuando los datos de la encuesta no permiten identificar claramente la exposición internacional de la industria en que cada individuo labora o en qué factor se ocupa principalmente, es posible inferir que en regiones donde el desempleo es más alto, la percepción sobre los beneficios asociados con la inversión extranjera deberían ser también más elevados. La gráfica 3 correlaciona datos agregados a nivel regional y por encuesta. Cada marcador muestra los resultados de una edición de la encuesta en una región (eje vertical) y el porcentaje de desempleo observado en promedio en esa región el año del levantamiento de la encuesta (eje horizontal). Para facilitar la visualización, se incluyen las líneas de tendencia de las regiones y del total nacional.

La distribución de los datos sugiere que, en promedio, las regiones con mayores índices de desempleo reciben porcentajes más altos de opiniones que asocian la inversión extranjera a beneficios, esto es, tienen actitudes más positivas respecto de los efectos de la inversión extranjera, lo cual es consistente con el modelo Heckscher-Ohlin (véase la tendencia del agregado nacional). Esta relación positiva entre mayores niveles de desempleo y porcentajes de opiniones positivas hacia la inversión extranjera es positiva también en cada una de las regiones, la asociación entre estas variables. Sin embargo, este análisis también revela diferencias regionales: la pendiente de la línea de tendencia de la región norte es menos pronunciada que la de las otras dos regiones, lo que indica que la asociación entre niveles de desempleo regional y actitudes 
positivas hacia la inversión extranjera es más estrecha en el centro y sur del país.

GRÁFICA 3

Desempleo y beneficios de la inversión extranjera

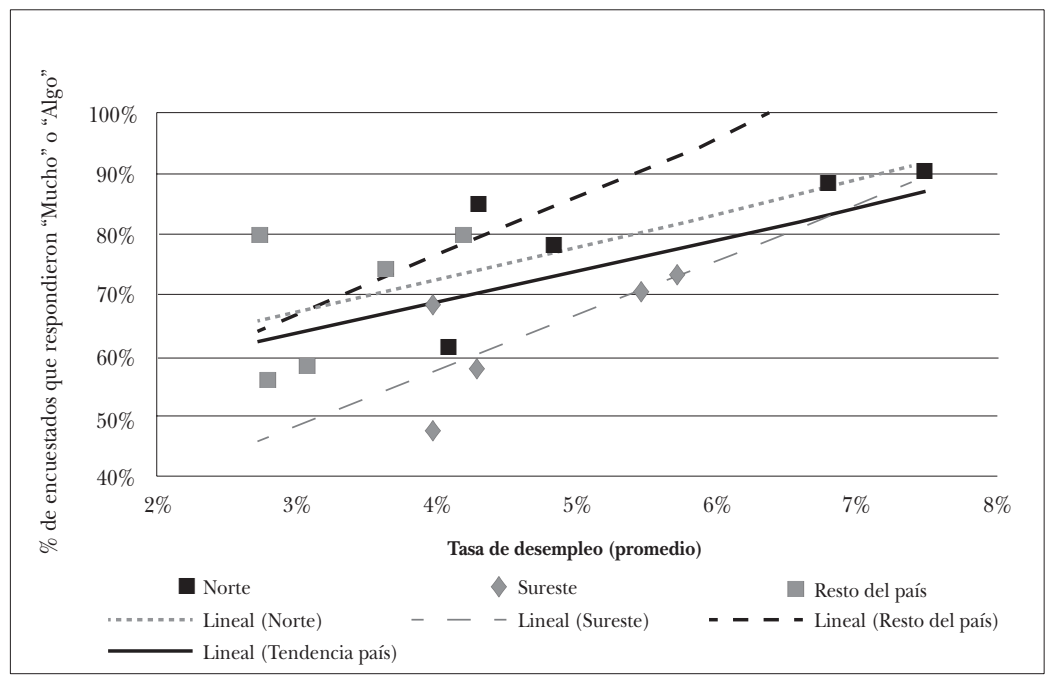

\subsection{Aceptación de la inversión extranjera, por sectores económicos}

Más allá de la creencia sobre la existencia de externalidades positivas asociadas a la inversión extranjera, una aproximación más directa a las actitudes en torno a la inversión extranjera es preguntarle a los entrevistados si el gobierno debería permitir o no la inversión extranjera en ciertos sectores de la economía. Debe tenerse presente que la respuesta a la primera pregunta (sobre los beneficios asociados con la inversión extranjera) tiene un componente cognoscitivo mayor e implica principalmente un juicio de causalidad. La segunda pregunta (si el gobierno debería permitir inversión extranjera en ciertos sectores de la economía), sin embargo, involucra un juicio de valor, independientemente 
del hecho de que se crea que, en general, existen externalidades positivas asociadas con la inversión extranjera. Las cinco encuestas incluyen la siguiente pregunta: "En su opinión ¿el gobierno mexicano debe permitir o no debe permitir que los extranjeros inviertan en [telefonía, electricidad, petróleo, medios de comunicación]?”. Las respuestas se describen a continuación.

Dos cuestiones merecen destacarse de las respuestas presentadas en la gráfica 4. Primero, es claro que la opinión de los mexicanos sobre cómo debería actuar el gobierno ante inversores extranjeros difiere significativamente dependiendo de la industria de la que se trate. De los cuatro sectores incluidos en las encuestas, los mexicanos se muestran más abiertos a la inversión extranjera en los sectores de telefonía y medios de comunicación $(54 \%$ del total de los encuestados en los cinco levantamientos, apoya la inversión extranjera en el primer sector, en tanto que $53.6 \%$ apoya la inversión extranjera en el segundo). Sin embargo, son más renuentes a proponer la inversión extranjera en el sector electricidad y, para nada sorpresivo, en la industria petrolera donde el Estado limita la inversión extranjera y mantiene monopolios (los niveles de apoyo son de 42.8 y $30.7 \%$ respectivamente).

Segundo, es también notable que la tendencia para las cuatro industrias es muy similar: una caída en el porcentaje de respuestas afirmativas 2006 con relación a 2004, y una lenta recuperación en 2008 hasta alcanzar niveles muy similares en 2010 que se mantienen, en términos generales, en la encuesta de 2012. Si se comparan estos datos con los presentados en la gráfica 2, es llamativo que el año en el que se recabó el menor porcentaje de respuestas a favor de permitir la inversión extranjera en todos los sectores (en 2006) es uno de los años en los que un alto porcentaje de encuestados $(67.9 \%)$ manifestaron opiniones positivas relativamente altas respecto a los beneficios asociados con la inversión extranjera, indicando que la inversión extranjera beneficiaba mucho o algo a México. Se puede pensar que el año 2006 representó una excepción a la tendencia general debido a la coyuntura política en el proceso electoral o a la discusión de propuestas de reforma energética. Sin embargo, dado que la serie temporal analizada comienza en 2004, es difícil determinar cuál era la tendencia general de 
aceptación de la inversión extranjera en estos sectores. En otras palabras, también es posible que las respuestas recogidas en 2004 hayan sido especialmente atípicas y que el resto de la serie muestre crecientes niveles de aceptación de la inversión extranjera en estos sectores a lo largo del tiempo.

\section{GRÁFICA 4}

En su opinión ¿el gobierno mexicano debe permitir o no debe permitir que los extranjeros inviertan en...? $\%$ de entrevistados que contestaron "Sí debe"

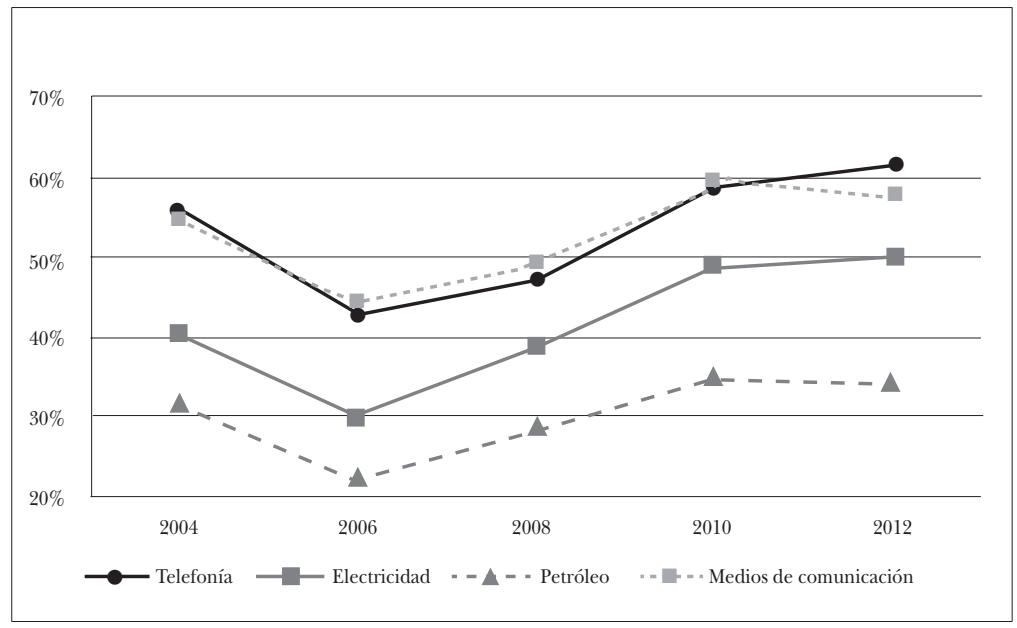

Los datos presentados en la gráfica 4 nos permiten reflexionar sobre cierta disonancia entre las respuestas obtenidas en la primera pregunta (beneficios de la inversión extranjera) y ésta. Numerosos entrevistados, aun considerando que la inversión extranjera puede traer beneficios para México, se oponen a la inversión extranjera en determinados sectores. Esto podría explicarse por dos razones. Primero, es posible que los entrevistados se hayan concentrado sólo en el aspecto económico al responder a la pregunta sobre los beneficios de la inversión extranjera, en tanto esta serie 
de preguntas (ya centradas en sectores específicos de inversión) motivaron un juicio que incluyó otros factores de tipo político, ideológico o incluso activó elementos de nacionalismo. ${ }^{38}$ Otra posibilidad es que la primera pregunta se haya basado más en la influencia del discurso presente, tanto en los medios de comunicación como entre autoridades políticas, sobre la necesidad de atraer inversión extranjera por los beneficios que ésta genera, en tanto las respuestas presentadas en la gráfica 4 pueden representar un juicio más particularizado y una evaluación más concreta de las opiniones personales.

\section{GRÁFICA 5}

En su opinión ¿`el gobierno mexicano debe permitir o no debe permitir que los extranjeros inviertan en telefonía?

$\%$ de entrevistados que contestaron "Sí debe"

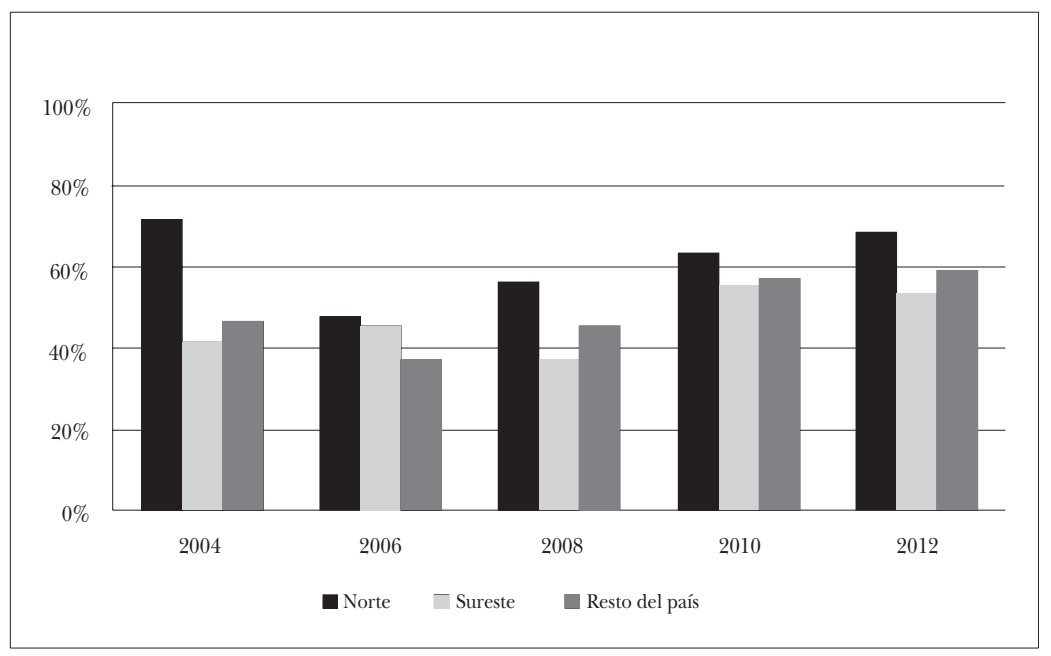

${ }^{38}$ Esto es consistente con los resultados de Kocher y Munushkin, quienes encuentran que el antiamericanismo influye negativamente en las actitudes hacia el libre comercio y la apertura de mercados financiero. Kocher y Minushkin, "Antiamericanismo y globalización económica: libre comercio, apertura de mercados y opinión pública en México". 
GrÁFICA 6

En su opinión ¿el gobierno mexicano debe permitir o no debe permitir que los extranjeros inviertan en electricidad? $\%$ de entrevistados que contestaron "Sí debe"

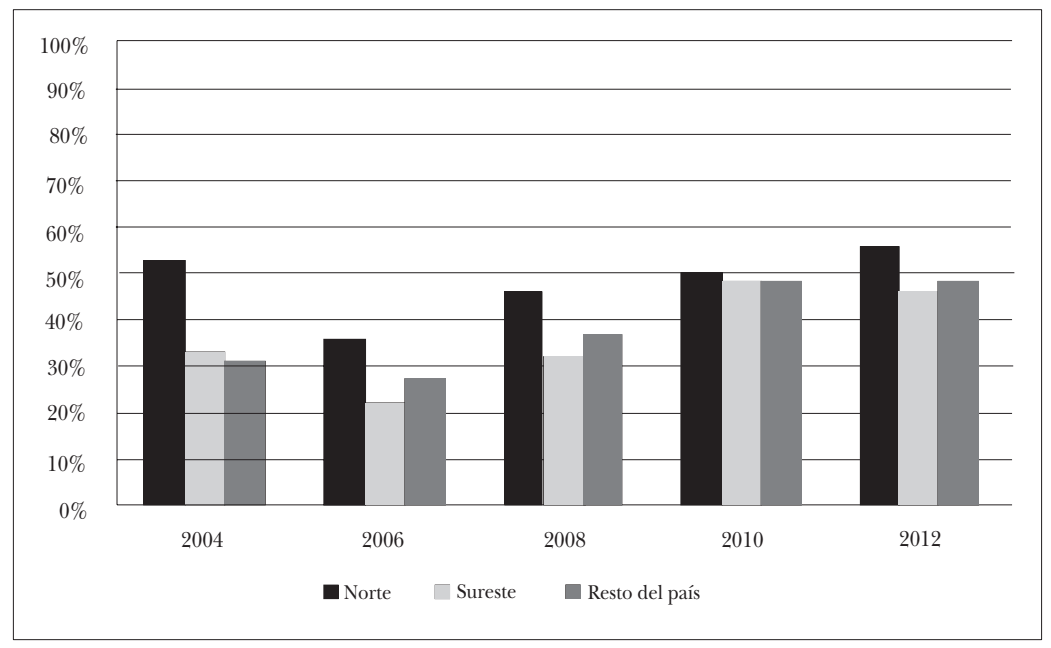

GRÁFICA 7

En su opinión ¿el gobierno mexicano debe permitir o no debe permitir que los extranjeros inviertan en petróleo?

$\%$ de entrevistados que contestaron "Sí debe"

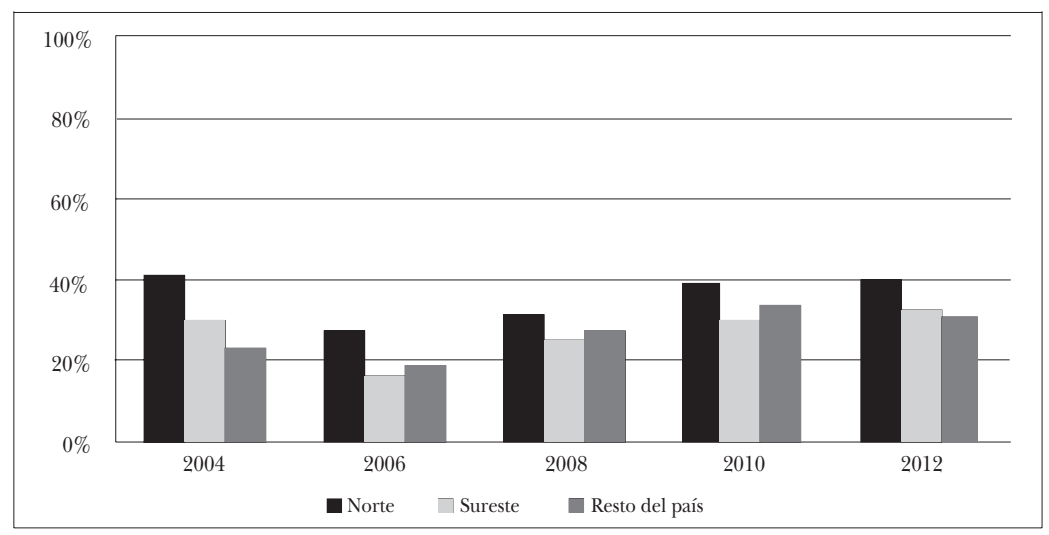


En las respuestas a estas preguntas también se observan marcadas diferencias regionales. Las gráficas 5 a 8 muestran el porcentaje de respuestas indicando que el gobierno mexicano debería permitir la inversión extranjera en los cuatro sectores bajo análisis, pero calculando los porcentajes en sub-muestras, dependiendo de la región en donde el encuestado vive.

\section{GRÁFICA 8}

En su opinión ¿el gobierno mexicano debe permitir o no debe permitir que los extranjeros inviertan en medios de comunicación?

$\%$ de entrevistados que contestaron "Sí debe"

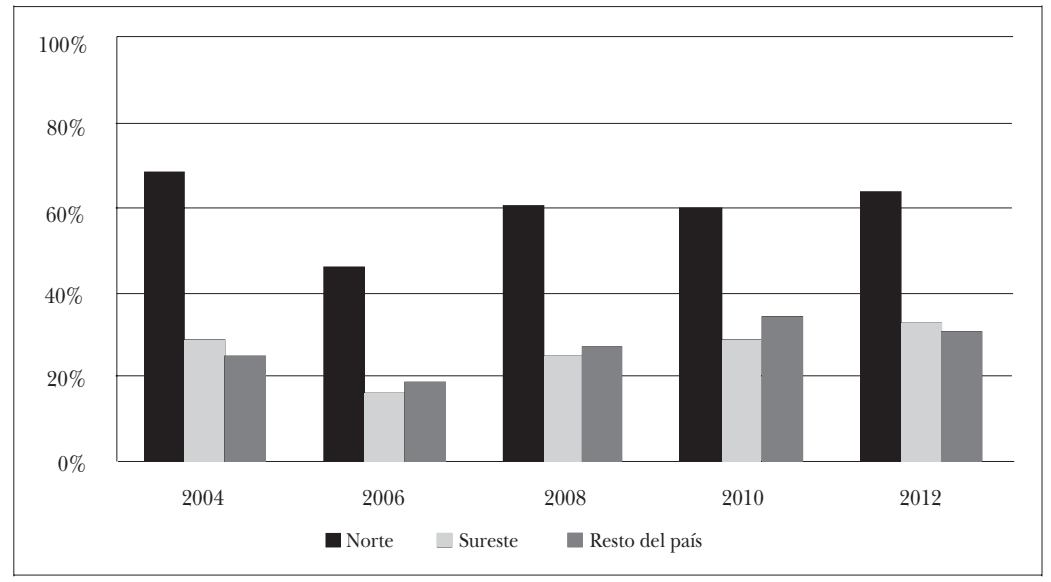

En general, puede apreciarse que, independientemente del sector de que se trate, los encuestados en la región norte del país son más favorables a permitir la inversión extranjera que el resto del país. Esta diferencia se hace más marcada en las opiniones sobre inversión extranjera en el sector de los medios de comunicación, en el que el porcentaje de opiniones favorables en la región norte es más del doble que la opinión favorable en las otras regiones del país (véase la gráfica 8). Sin embargo, no hay diferencias significativas entre las opiniones recabadas en la región sureste y en el resto del país. 
4.3 Sobre la importancia de la atracción de inversión extranjera como objetivo de política exterior

Aunque la creencia sobre la existencia de beneficios asociados con la inversión extranjera se relaciona con las preferencias de política pública manifestadas por los entrevistados, ambas preguntas son lógicamente independientes, y han obtenido resultados no necesariamente consistentes, tal como lo muestran las respuestas a la pregunta "¿qué tan importante debe ser cada uno de los siguientes objetivos para la política exterior de México?: Atraer inversión extranjera a México”.

Del conjunto de las respuestas obtenidas en los cuatro levantamientos que aquí analizamos (8 380 respuestas), $67.95 \%$ señaló que atraer inversión extranjera es muy importante, en tanto que el $24 \%$ indicó que es algo importante. ${ }^{39}$ Sólo 6 y $1.8 \%$ de los entrevistados indicaron que la atracción de inversión extranjera es un objetivo de política exterior poco o nada importante respectivamente. La gráfica 9 muestra la distribución de las respuestas en los distintos levantamientos.

¿Cómo podemos evaluar estos aparentemente muy altos niveles de importancia atribuida al objetivo de atraer inversión extranjera en el marco de la política exterior nacional? Dos parámetros resultan de interés. En primer lugar, comparamos la importancia atribuida a la atracción de inversiones en el marco de los otros objetivos de política exterior incluidos en la encuesta. Como muestra la gráfica 10, el objetivo que nos interesa se ubica en el séptimo lugar, entre las dieciséis opciones que la encuesta examina, con base en las respuestas que lo califican como "muy importante". Esta importancia relativa se mantiene en el año 2012, aun a pesar de la caída en el apoyo a este objetivo con relación a la encuesta de 2010.

Otro parámetro interesante es tomar como referencia las respuestas a la misma pregunta en otros países latinoamericanos en los que se ha aplicado la encuesta. ${ }^{40}$ La gráfica 11 muestra

${ }^{39}$ En el año 2004 esta pregunta no se realizó.

${ }^{40}$ Los cuestionarios de las encuestas de Las Américas y el Mundo comparten una batería principal de preguntas comparables entre países. Para mayor información véase http:/ / www.lasamericasyelmundo.org/ 
los porcentajes de encuestados que respondieron a la pregunta sobre la importancia de la inversión extranjera en el marco de la política exterior de sus respectivos países. Por razones de brevedad y claridad, presentamos solamente las últimas respuestas disponibles. ${ }^{41}$ La gran mayoría de los entrevistados (más del $80 \%$ ) en los seis países opinan que atraer inversión extranjera es un objetivo de política exterior muy o algo importante. Sin embargo, el porcentaje de entrevistados que consideran la atracción de inversión extranjera como muy importante presenta mayor variación. Los niveles aparentemente muy altos de importancia atribuida al objetivo de atraer inversión extranjera en el marco de la política exterior mexicana están lejos de ser los más altos que se han registrado en otros países latinoamericanos, aun cuando se encuentran por encima de los niveles relevados en Perú y Brasil.

\section{GrÁFICA 9}

Dígame, ¿qué tan importante debe ser cada uno de los siguientes objetivos para la política exterior de México?: Atraer inversión extranjera a México

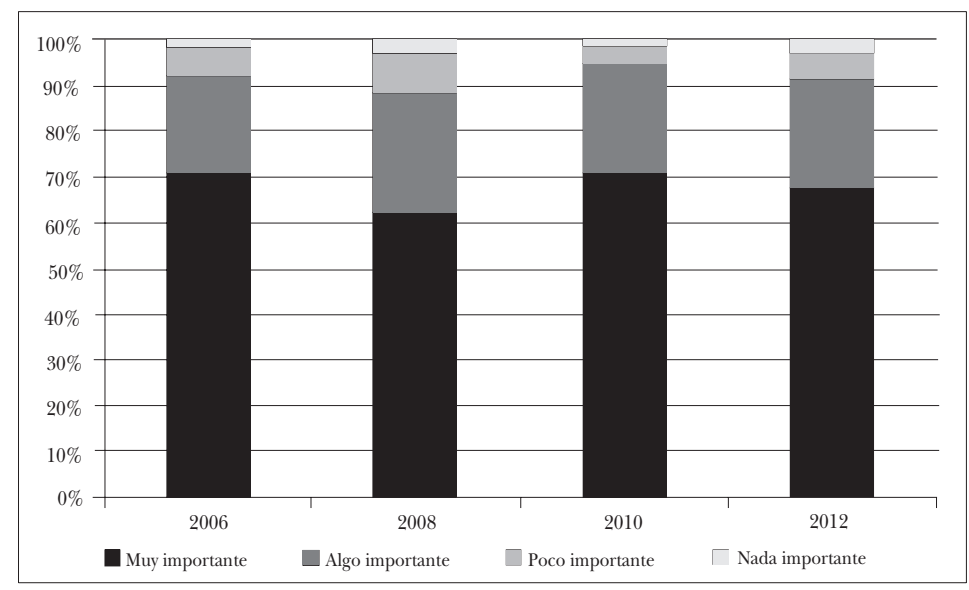

${ }^{41}$ La encuesta no se aplicó en todos los países en 2012. Los datos para Chile son de la encuesta levantada en 2008, en tanto los datos para Perú y Brasil son del año 2010. El anexo 2 presenta las respuestas a esta pregunta en todos los países y todos los años en que se aplicó. 


\section{GRÁFICA 10}

Objetivos para la política de México:

Porcentaje de respuestas "muy importante" en 2010 y 2012)

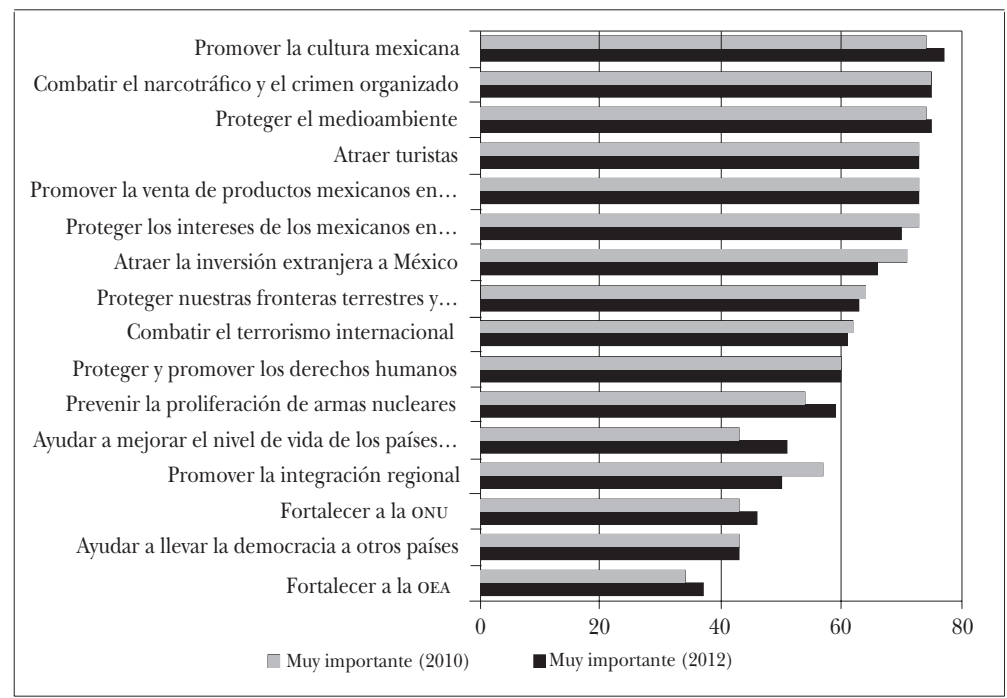

Estas diferencias son especialmente interesantes si se tiene en cuenta que no guardan relación con los flujos de inversión extranjera que estos países reciben: mientras que Brasil es el principal receptor de inversión extranjera en América Latina (y séptima economía en el mundo en volumen de inversión extranjera recibida), México es el segundo y Chile el tercero (ubicando los puestos número 12 y 18 respectivamente). ${ }^{42}$

Como se puede ver en la gráfica 12, en esta pregunta también se registran importantes diferencias regionales en las opiniones. Con excepción del año 2010, la proporción de encuestados que sostienen que la promoción de inversión extranjera es un objetivo importante de política exterior es mayor en la región norte que en el resto

42 unctad, Global Investment Trends Monitor, núm. 15, 28 de enero de 2014, pág. 6. Versión en línea en http://unctad.org/en/PublicationsLibrary/webdiaeia 2014d1_en.pdf 
del país. Esta proporción es la más baja en la región sureste, que reproduce patrones regionales observados en otras preguntas.

\section{GRÁFICA 11}

Objetivos de política exterior: Atraer inversión extranjera a [PAÍs] - Últimos datos disponibles

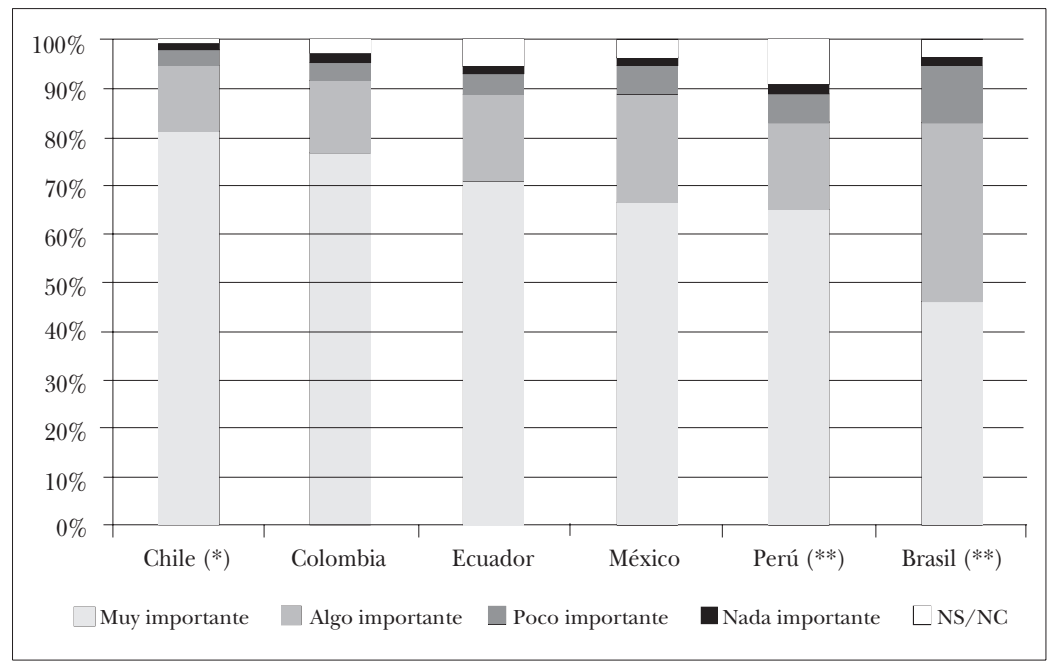

Nota: Los datos de Colombia, Ecuador y México corresponden al año 2012. Para Perú y Brasil usamos datos del año 2010 (**), y para Chile datos del año 2008 (*)

En la edición de 2010, sin embargo, las diferencias regionales parecen esfumarse: el porcentaje de entrevistados que consideran que la atracción de inversión extranjera es importante en las regiones sureste y resto del país es especialmente alto en relación con años anteriores, superando incluso a la región norte (aunque las diferencias entre las tres regiones no son estadísticamente significativas). Estos altos niveles de apoyo a políticas de atracción de inversión extranjera pueden interpretarse a la luz de otros resultados ya discutidos. Por un lado, en este mismo año la encuesta registró los mayores niveles de respuestas que consideran que la inversión extranjera beneficia a México, Por otra parte, en el año 2009 se 
produce una importante caída en el producto interno bruto, asociado con un incremento marcado en los niveles de desempleo en todo el país y en cada una de las regiones analizadas (recuérdese que los años 2009 y 2010 registran los niveles de desempleo más altos en el país desde 1996). ${ }^{43}$ Si bien este análisis no nos permite establecer relaciones de causalidad, dada la asociación positiva entre desempleo regional y opiniones favorables hacia la inversión extranjera, y los niveles récord de desempleo alcanzados en los años 2009-2010, no es sorprendente encontrar niveles particularmente altos de respuestas positivas en esta edición de la encuesta.

\section{GRÁFICA 12}

Dígame, ¿qué tan importante debe ser cada uno de los siguientes objetivos para la política exterior de México?: Atraer inversión extranjera a México $\%$ de encuestados que lo considera muy o algo importante

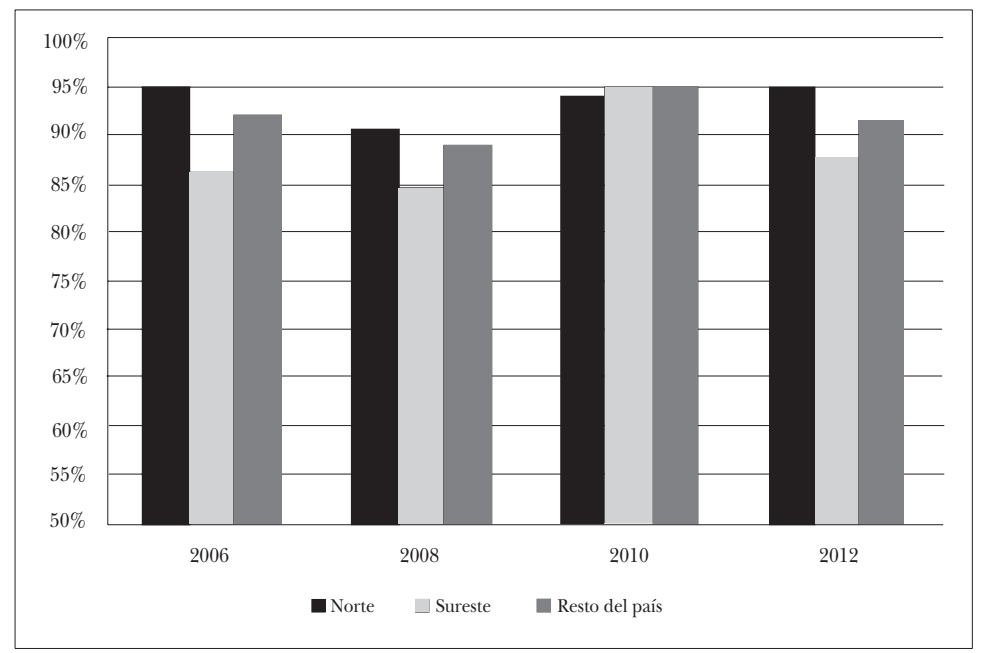

Nota: El eje vertical se presenta truncado para facilitar la visualización de los resultados.

43 Según datos de desempleo como porcentaje del total de la fuerza del trabajo del Banco Mundial en http:/ / databank.worldbank.org/data/views/reports/ tableview.aspx\#s_u Consultado el 7/10/2014. 


\subsection{Sobre consistencia entre opiniones}

El análisis conjunto de las respuestas descritas en los apartados anteriores expone una aparente inconsistencia entre la valoración positiva de la inversión extranjera y los niveles de prioridad de la atracción de inversión extranjera en la agenda exterior de México. En principio, es de esperar cierta correlación entre las opiniones que un mismo sujeto tiene sobre los beneficios que trae la inversión extranjera y qué tan deseable es que la atracción de inversión sea un objetivo prioritario de política exterior. En otras palabras, tiene sentido proponer la atracción de inversión como objetivo importante de política exterior sólo si se considera que la inversión extranjera trae beneficios aparejados, pero no si se considera que no trae ningún beneficio para México. Sin embargo, la correlación entre ambas respuestas es sólo de .179 (con un margen de confianza de $99.9 \%$ ).

La gráfica 13 proporciona un cuadro más detallado de la distribución de las respuestas a estas dos preguntas.

Las respuestas más consistentes son las que se ubican en la diagonal con origen en el ángulo inferior izquierdo: son personas que coinciden en el nivel de beneficios que le atribuyen a la inversión extranjera, y en la importancia que piensan debería otorgarse al objetivo de atraer inversión en la agenda exterior de México. Sin embargo, estas respuestas representan sólo $44.5 \%$ de los casos. Los casos restantes pueden ubicarse en dos grupos. El primer grupo está compuesto por el $12.5 \%$ de los entrevistados que se ubican "por debajo de la diagonal". Las respuestas de este grupo sugieren la existencia de encuestados que no estiman importante que la política exterior de México tenga por objetivo atraer inversión, aun creyendo que la inversión extranjera trae beneficios para el país. Esto puede deberse a preferencias estrictas sobre la agenda internacional (gente que piensa que "la diplomacia debe usarse para otras cosas") o a desconocimiento sobre las actividades de promoción internacional del país que pueden realizarse como política de Estado. 
GRÁfica 13

Respuestas a las preguntas sobre inversión

Los círculos indican el número de respuestas totales en las ediciones 2006, 2008, 2010 y 2012 de la encuesta

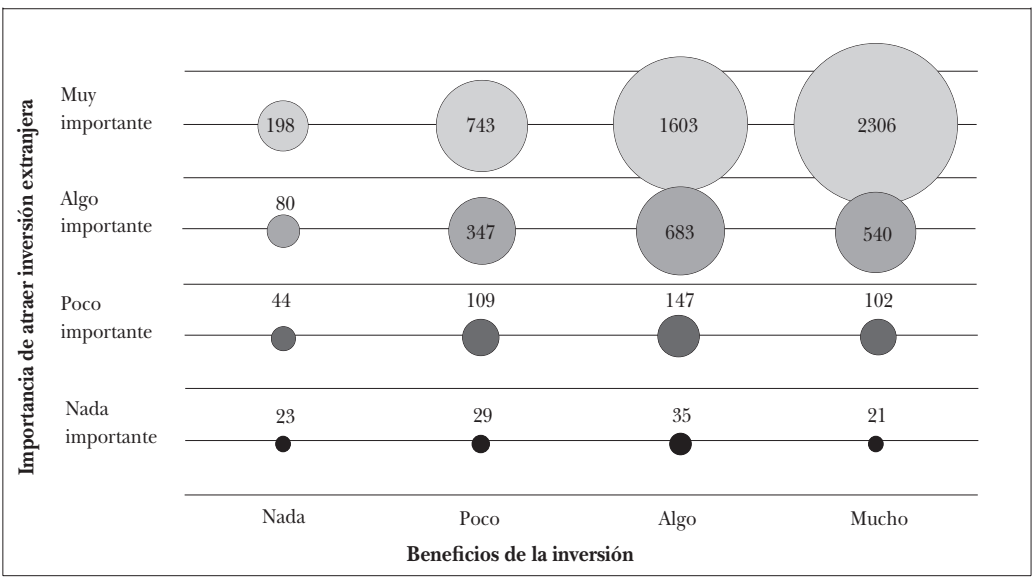

El segundo grupo refleja una mayor inconsistencia en sus respuestas. El $43 \%$ de los encuestados estiman que la atracción de inversión debe ser parte de los objetivos de política exterior de México, aun cuando no atribuye mayores beneficios a la inversión extranjera. Cabe señalar, sin embargo, que este grupo incluye a 1603 sujetos (22.9\%) que opinan que la atracción de inversión es un objetivo de política exterior "muy importante", aun cuando creen que la inversión trae "algunos" beneficios, lo cual puede explicarse con una lógica utilitarista (la política exterior debería intentar atraer inversión aunque la inversión extranjera traiga "sólo" algunos beneficios). Algo similar podría ocurrir con los entrevistados que opinan que la atracción de inversión es un objetivo de política exterior "algo importante", aun cuando creen que la inversión trae "pocos" beneficios (5\%). Más difícil de explicar es el restante $15 \%$ de encuestados que opinan que la atracción de inversión extranjera debería ser un objetivo de política exterior, aun cuando la inversión extranjera proporcione poco o ningún beneficio. 


\section{Conclusiones}

Este artículo presenta una aproximación descriptiva a las actitudes de los mexicanos hacia la inversión extranjera. Una serie de cuestiones aparece en el análisis aquí realizado. En primer lugar, las opiniones en esta materia presentan una variación interesante a lo largo del tiempo. La crisis financiera internacional no parece haber afectado significativamente (ni de manera persistente) las opiniones positivas sobre la inversión extranjera. Esto es consistente con otros análisis de los efectos de crisis económicas sobre actitudes de apoyo a políticas de libre mercado en América Latina. ${ }^{44}$ Por el contrario, se observa un crecimiento en las opiniones positivas respecto a la admisibilidad de inversión extranjera en sectores críticos de la economía mexicana desde el año 2006 en adelante. Sin embargo, y como mencionamos anteriormente, con la información disponible no podemos establecer si el año 2006 muestra una excepcional caída en la aceptación de inversión extranjera en los sectores analizados, o si los niveles de aceptación registrados en el levantamiento del año 2004 eran atípicamente altos. Esto abre preguntas para futura investigación sobre la relación entre las opiniones de la ciudadanía en materia de inversión extranjera y variables específicas de la coyuntura económica y política, en particular, la exposición al debate público sobre las ventajas de la apertura, así como la relación entre estas opiniones y el volumen y tipos de inversión extranjera que recibe la región en donde vive el encuestado.

Los datos examinados sugieren cierta relación a nivel agregado entre la percepción de beneficios asociados con la inversión extranjera y el nivel de desempleo en distintas regiones mexicanas. Esta relación debería ser explorada con más profundidad y de manera multivariada para establecer si las relaciones entre estas variables se mantienen a nivel individual. Sin embargo, las diferencias regionales observadas parecen obedecer a otros factores, más allá de los niveles de desempleo. Entendemos que los mayores niveles de actitudes positivas frente a la inversión extranjera, tanto

${ }^{44}$ Carol Graham y Sandip Sukhtankar, "Does Economic Crisis Reduce Support for Markets and Democracy in Latin America? Some Evidence from Surveys of Public Opinion and Well Being", Journal of Latin American Studies, vol. 36, núm. 2, 2004. 
en general como en sectores específicos encontrados en la región norte, pueden tener una raíz geográfica. Es posible que una mayor proximidad y contactos con los Estados Unidos, principal fuente de inversión extranjera en México, ${ }^{45}$ tengan un efecto en las percepciones frente a los beneficios que trae la inversión extranjera y en la importancia que la atracción de inversión extranjera debería tener en el marco de la política exterior mexicana. Sin embargo, cabe destacar que estas actitudes más positivas hacia la inversión extranjera en la región Norte contrastan con las expectativas derivadas de quienes señalan las desventajas de la industria de maquila, ${ }^{46}$ dado que precisamente es en esta región donde la inversión extranjera se asocia más fuertemente con la maquila.

Otro elemento interesante que las encuestas ponen de manifiesto es una serie de "inconsistencias" en opiniones que, dada su naturaleza, deberían estar relacionadas. ${ }^{47} \mathrm{Si}$ bien esto puede deberse a problemas en la comprensión de las preguntas de la encuesta, entendemos que sugiere que, como destacan Chattopadhyay y Graham, las percepciones públicas no siempre están informadas por condiciones objetivas, y en buena medida esto se debe a que la información con que cuentan los ciudadanos es imperfecta. ${ }^{48}$ Una serie de factores personales que no hemos analizado aquí, y que incluyen orientaciones ideológicas, historia personal, confianza en los mecanismos de mercado y hasta sofisticación de conocimiento, pueden explicar estas divergencias. Afortunadamente, la base de datos que hemos utilizado en este trabajo permitirá en el futuro analizar otras dimensiones que afectan las actitudes de los mexicanos hacia la inversión extranjera.

45 Ana Carolina Garriga, "Inversión extranjera directa en México: comparación entre la inversión procedente de los Estados Unidos y del resto del mundo", Documento de Trabajo DTEP, núm. 266, México, Centro de Investigación y Docencia Económicas, 2014.

${ }^{46}$ Véanse, por ejemplo, León Benedesky, Enrique de la Garza, Javier Meloza y Carlos Salas, "La industria maquiladora de exportación en México: mitos, realidades y crisis”, Estudios Sociológicos, vol. 22, núm. 2, 2004, pp. 283-314; Luisa Gabayet, “Atrapadas entre la flexibilidad y la precariedad en el trabajo: las obreras de la industria metropolitana en Guadalajara, 1998-2004”, Desacatos, núm. 21, 2006, pp. 29-50.

${ }^{47}$ Véase la gráfica 13.

${ }^{48}$ Soumya Chattopadhyay y Carol Graham, Public Opinion Trends in Latin America (and the U.S.): How Strong Is Support for Markets, Democracy, and Regional Integration?, Washington, Brookings Institution Press, 2008. 


\section{Anexo 1}

Preguntas utilizadas en este estudio: redacción y respuestas disponibles en distintas ediciones de la encuesta

Año Tema: Atracción de inversión

2008 Pregunta 19_10: Dígame, ¿qué tan importante debe ser cada uno de los siguientes objetivos para la política exterior de México: muy importante, algo importante, poco importante o nada importante? 10- Atraer inversión extranjera a México Respuestas: Muy importante, Algo importante, Poco importante, Nada importante, Ns, $\mathrm{NC}$

2010 Ídem Encuesta 2008

2012 Pregunta 32_10 A: Dígame ¿qué tan importante debe ser cada uno de los siguientes objetivos para la política exterior de México: muy importante, algo importante, poco importante o nada importante? 10- Atraer inversión extranjera a México

Respuestas: Muy importante, Algo importante, Poco importante, Nada importante, NS, NC

Pregunta 32_10 B: Utilizando una escala del 1 a 7 donde 1 significa nada importante y 7 muy importante dígame ¿qué tan importante debe ser cada uno de los siguientes objetivos para la política exterior de México 10- Atraer inversión extranjera a México

Respuestas: Calificación 1 a 7, NS, NC

Año Tema: Beneficios de la inversión

2008 Pregunta 29 A: ¿Qué tanto cree que la inversión extranjera beneficia a México?

Respuestas: Mucho, Algo, Poco, Nada, NS, NC

Pregunta 29 B: ¿Qué tanto cree que la inversión extranjera beneficia a México?

Respuestas: Mucho, Bastante, Poco, Nada, NS, NC

2010 Pregunta 38: ¿Qué tanto cree que la inversión extranjera directa beneficia a México?

Respuestas: Mucho, Algo, Poco, Nada, Ns, NC 
2012 Pregunta 44 A: ¿Qué tanto cree que la inversión extranjera directa beneficia a México?

Respuestas: Mucho, Algo, Poco, Nada, Ns, NC

Pregunta 44 B: La inversión extranjera en México también tiene ventajas (por ejemplo, nuevos empleos, y tecnología) y desventajas (por ejemplo, el cierre de algunas empresas mexicanas y que las utilidades se vayan a otros países). Tomando esto en cuenta ¿qué tanto cree que la inversión extranjera directa beneficia a México?

Respuestas: Mucho, Algo, Poco, Nada, NS, NC

Año Tema: Inversión extranjera en sectores

2008 Pregunta 30_1: En su opinión, ¿el gobierno mexicano debe permitir o no debe permitir que los extranjeros inviertan en...? 30_1 Telefonía

30_2 Electricidad

30_3 Producción, explotación y distribución de petróleo

30_4 Medios de comunicación como televisoras y periódicos Respuestas: Sí, No, NS, NC

2010 Ídem Encuesta 2008

2012 Pregunta Mx2_1A: En su opinión, ¿el gobierno mexicano debe permitir o no debe permitir que los extranjeros invier$\tan$ en...?

Mx2_1A Telefonía

Mx2_2A Electricidad

Mx2_3A Producción, explotación y distribución de petróleo Mx2_4A Medios de comunicación como televisoras y periódicos

Respuestas: Sí, No, NS, NC

Pregunta Mx2_1B: En su opinión, ¿el gobierno mexicano debe permitir o no debe permitir que los extranjeros inviertan en...? Mx2_1B Telefonía

Mx2_2B Electricidad

Mx2_3B Petróleo

Mx2_4B Medios de comunicación

Respuestas: Sí, No, NS, NC 
Anexo 2

Gráfica adicional

Dígame, ¿qué tan importante debe ser cada uno de los siguientes objetivos para la política exterior de su país?:

Atraer inversión extranjera

$\%$ de encuestados que lo considera muy importante

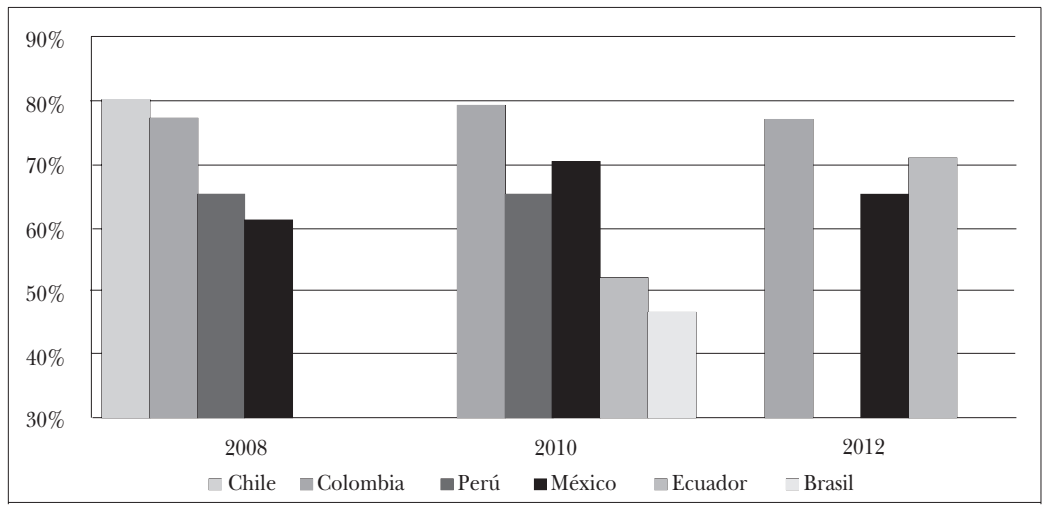

\section{BibLIOGRAFÍA}

Aguilar, Rosario, “¿Emociones y razón?: el uso estratégico de emociones en los anuncios de la campaña presidencial de 2012", Política y Gobierno, vol. 20, núm. 1, 2013, pp. 141-158.

Ardanaz, Martin, Victoria Murillo y Pablo Pinto, "Sensitivity to Issue Framing on Trade Policy Preferences: Evidence from a Survey Experiment”, International Organization, vol. 67, núm. 2, 2013, pp. 411-437.

Baker, Andy, "Why is Trade Reform so Popular in Latin America?: A Consumption-Based Theory of Trade Policy Preferences", World Politics, vol. 55, núm. 3, 2003, pp. 423-455.

, "Who Wants to Globalize? Consumer Tastes and Labor Markets in a Theory of Trade Policy Beliefs", American Journal of Political Science, vol. 49, núm. 4, 2005, pp. 924-938.

Balistreri, Edward, "The Performance of the Heckscher-Ohlin-Vanek Model in Predicting Endogenous Policy Forces at the Individual Level", Canadian Journal of Economics, vol. 30, núm. febrero de 1997, pp. 1-17. 
Benedesky, León, Enrique de la Garza, Javier Meloza y Carlos Salas. "La industria maquiladora de exportación en México: mitos, realidades y crisis”, Estudios Sociológicos, vol. 22, núm. 2, 2004, pp. 283-314.

Bhagwati, Jagdish, "Why Multinationals Help Reduce Poverty", World Economy 30, núm. 2, 2007, pp. 211-228.

Borensztein, Eduardo, Jose de Gregorio y Jong-Wha Lee. "How Does Foreign Direct Investment Affect Economic Growth?”, Journal of International Economics, vol. 45, 1998, pp. 115-135.

Buendía Laredo, Jorge y Ma. Fernanda Somuano, "Participación electoral en nuevas democracias: la elección presidencial de 2000 en México”, Política y Gobierno, vol. 10, núm. 2, 2003, pp. 289-323.

Chattopadhyay, Soumya y Carol Graham, Public Opinion Trends in Latin America (and the U.S.): How Strong is Support for Markets, Democracy, and Regional Integration?, Brookings Institution Press, 2008.

Dussel Peters, Enrique, "La inversión extranjera en México", Series de Desarrollo Productivo CEPAL, núm 80, Santiago de Chile, Naciones Unidas, 2000.

Fordham, Benjamin y Katja Kleinberg, "How Can Economic Interests Influence Support for Free Trade?”, International Organization, vol. 66, núm. 2, 2012, pp. 311-328.

Gabayet, Luisa, "Atrapadas entre la flexibilidad y la precariedad en el trabajo: las obreras de la industria metropolitana en Guadalajara, 1998-2004", Desacatos, núm. 21, 2006, pp. 29-50.

Garriga, Ana Carolina, "Inversión extranjera directa en México: comparación entre la inversión procedente de los Estados Unidos y del resto del mundo", Documento de Trabajo DTEP, núm. 266, México, Centro de Investigación y Docencia Económicas, 2014.

-, "Política partidaria e inversión extranjera directa: el caso de los estados mexicanos", Documento de Trabajo DTEP, núm. 256, México, Centro de Investigación y Docencia Económicas, 2013.

Graham, Carol y Sandip Sukhtankar, "Does Economic Crisis Reduce Support for Markets and Democracy in Latin America? Some Evidence from Surveys of Public Opinion and Well Being", Journal of Latin American Studies, vol. 36, núm. 2, 2004, pp. 349-377.

Greene, Kenneth, "Campaign Persuasion and Nascent Partisanship in Mexico's New Democracy”, American Journal of Political Science, vol. 55, núm. 2, 2011, pp. 398-416. 
Hanson, Gordon, Kenneth Scheve y Matthew Slaughter, "Public Finance and Individual Preferences Over Globalization Strategies", Economics E̊ Politics, vol. 19, núm. 1, 2007, pp. 1-33.

Hicks, Raymond, Helen Milner y Dustin Tingley, "Trade Policy, Economic Interests, and Party Politics in a Developing Country: The Political Economy of CAFTA-DR", International Studies Quarterly, 2013, DOI: 10.1111 isqu. 12057

Hiscox, Michael, "Through a Glass and Darkly: Attitudes toward International Trade and the Curious Effects of Issue Framing", International Organization, vol. 60, núm. 3, 2006, pp. 755-780.

$\longrightarrow$ y Brian Burgoon, "The Mysterious Case of Female Protectionism: Gender Bias in Attitudes Towards Globalization”, American Political Science Association, Philadelphia, 2003.

Jakobsen, Jo y Tor Jakobsen, "Economic Nationalism and FDI: The Impact of Public Opinion on Foreign Direct Investment in Emerging Markets, 1990-2005”, Society and Business Review, vol. 6, núm. 1, 2011, pp. 61-76.

Jakobsen, Tor, "Economic Nationalism and Foreign Direct Investment. A Great Risk for Investors", http://www.popularsocialscience.com/ 2012/11/26/economic-nationalism-and-foreign-direct-investment-agreat-risk-for-investors/. Consultado en 20/2/2014.

Jensen, Nathan y Guillermo Rosas, "Foreign Direct Investment and Income Inequality in Mexico, 1990-2000", International Organization, vol. 61, núm. 3, 2007, pp. 467-487.

Kocher, Matthew Adam y Susan Minushkin, "Antiamericanismo y globalización económica: libre comercio, apertura de mercados y opinión pública en México", Política y Gobierno, vol. 14, núm. 1, 2007, pp. 77-115.

Kwon, Hyeok, "Globalization, Cultural Openness, and Public Preferences for East Asian Economic Integration in South Korea", International Journal of Public Opinion Research, vol. 23, núm. 1, 2011, pp. 2-23.

Lawson, Chappell y James McCann, “Television News, Mexico's 2000 Elections and Media Effects in Emerging Democracies”, British Journal of Political Science, vol. 35, núm. 1, 2005, pp. 1-30.

Li, Xiaoying y Xiaming Liu, "Foreign Direct Investment and Economic Growth: An Increasingly Endogenous Relationship", World Development, vol. 33, núm. 3, 2005, pp. 393-407.

Mansfield, Edward y Diana Mutz, "Support for Free Trade: Self-Interest, 
Sociotropic Politics, and Out-Group Anxiety", International Organization, vol. 63, núm. 3, 2009, pp. 425-457.

Mayda, Anna Maria y Dani Rodrik, "Why Are Some People (and Countries) More Protectionist than Others?", European Economic Review, vol. 49, núm. 6, 2005, pp. 1393-1430.

Medrano, Juan Díez y Michael Braun, "Uninformed Citizens and Support for Free Trade”, Review of International Political Economy, vol. 19, núm. 3, 2011, pp. 448-476.

Modya, Ashoka y Antu Panini Murshid, "Growing Up with Capital Flows", Journal of International Economics, vol. 65, 2005, pp. 249-266.

Moran, Theodore, Beyond Sweatshops, Washington, Brookings Institution Press, 2002.

Moreno, Alejandro, El votante mexicano: democracia, actitudes políticas y conducta electoral, México, FCE, 2003.

$\longrightarrow$, La decisión electoral. votantes, partidos y democracia en México, México, Porrúa, 2009.

Mukherjee, Bumba, Dale Smith y Quan Li, "Labor (Im)mobility and the Politics of Trade Protection in Majoritarian Democracies", The Journal of Politics, vol. 71, núm. 1, 2009, pp. 291-308.

O'Rourke, Kevin y Richard Sinnott, "The Determinants of Individual Trade Policy Preferences: International Survey Evidence”, Brookings Trade Forum, 2001, pp. 157-196.

Pandya, Sonal, "Labor Markets and the Demand for Foreign Direct Investment”, International Organization, vol. 64, núm. 3, 2010, pp. 389-409.

Pinto, Pablo, Partisan Investment in the Global Economy: Why the Left Loves Foreign Direct Investment and FDI Loves the Left, Cambridge, Cambridge University Press, 2013.

Romero, José, "Inversión extranjera directa y crecimiento económico en México: 1940-2010”, Documento de Trabajo, núm. 12, Mexico, El Colegio de México, 2012.

Scheve, Kenneth y Matthew Slaughter, "What Determines Individual Trade-Policy Preferences?”, Journal of International Economics, vol. 54, núm. 2, 2001, pp. 267-292.

- "Economic Insecurity and the Globalization of Production", American Journal of Political Science, vol. 48, núm. 4, 2004, pp. 662-674. Seligson, Mitchell, "Popular Support for Regional Economic Integration 
in Latin America", Journal of Latin American Studies, vol. 31, núm. 1, 1999, pp. 129-150.

Stokes, Susan (ed.), Public Support for Market Reforms in New Democracies, Cambridge Studies in Comparative Politics, Cambridge, UK; Nueva York, Cambridge University Press, 2001.

Tickner, Arlene y Felipe Botero, Colombia y el mundo 2010. Opinión pública y política internacional, Bogotá, Universidad de los Andes, 2011.

UNCTAD, Global Investment Trends Monitor, núm. 15, 28 de enero de 2014.

Velázquez Flores, Rafael y Jorge Schiavon, "Opinión pública y política exterior: percepciones y preferencias de los mexicanos”, Revista Mexicana de Opinión Pública, vol. 4, núm. abril de 2008, pp. 73-91.

Zhang, Kevin Honglin, "Does Foreign Direct Investment Promote Economic Growth? Evidence from East Asia And Latin America”, Contemporary Economic Policy, vol. 19, núm. 2, 2001, pp. 175-185. 